\title{
The effect of varying nitrogen and phosphorus availability on nutrient use by Larrea tridentata, a desert evergreen shrub
}

\author{
Kate Lajtha and Melanie Klein
}

Oecologia (Berlin) (1988) 75:348-353

The values along the $\mathrm{x}$-axis of fig. 1 should be multiplied by 10; the correct axis should run from 0.4 to 250 , not .04-25, thus making $\mathrm{N}: \mathrm{P}$ solution ratios agree with values in Table 1. 